\title{
Cooperativismo de plataforma e suas contradições: análise de iniciativas da área de comunicação no Platform.Coop
}

\author{
Platform Cooperativism and its contradictions: an analysis of media \\ initiatives on Platform.Coop
}

Rafael Grohmann *

\section{RESUMO}

A partir de discussões sobre
cooperativas, capitalismor e
cooperativismo de plataforma, o artigo
analisa os textos de apresentação de
iniciativas da área de comunicação
presentes no site Platform.Coop,
referência mundial no cooperativismo de
plataforma, com o objetivo de
compreender que valores e visões de
mundo fomentam, com seus alcances e
limites, mostrando pistas de como
entendem o trabalho cooperativo e o
próprio trabalho na área da comunicação.
A pesquisa, então, aponta as
contradições nos enunciados das
iniciativas do cooperativismo de
plataforma, envolvendo ajustamentos às
prescrições do modo de produção
capitalista.

Palavras-chave: Cooperativismo; Plataforma; Trabalho; Comunicação.

\begin{abstract}
The paper analyzes the presentation texts of cooperatives with media workers present in the Platform.Coop site, a world reference in platform cooperativism, with the aim of understanding what are their values and world views, with scope and limits. From discussions on the world of work in the area of communication, between individualization and collective forms of organization, the paper also aims to understand theoretically cooperative issues, especially in the area of communication, platform capitalism and platform cooperativism. The research, then, points out the contradictions in the statements of the initiatives of the platform cooperativism, involving adjustments to the prescriptions of the capitalist mode of production.
\end{abstract}

Keywords: Cooperativism; Platform; Labour; Communication.

\section{INTRODUÇÃO}

No mundo do trabalho em comunicação, pesquisas fora (McKercher; MOSCO, 2009; Hesmondhalgh, 2013; Cohen, 2016) e dentro do Brasil (Casaqui; Lima; Riegel, 2011; Mick; Lima, 2013; Fígaro, Nonato; Grohmann, 2013) têm apontado para flexibilização, precarização e individualização das situações de trabalho, envolvendo desde uma dimensão contratual até a mais estrutural da própria organização do trabalho, a partir de, por exemplo, contratos part-time, freelancers e microempreendedores individuais.

\footnotetext{
* Doutor em Ciências da Comunicação pela Universidade de São Paulo.Professor do Programa de PósGraduação em Comunicação da Faculdade Cásper Líbero. Endereço profissional: Avenida Paulista, 900, Bela Vista, CEP 01310-940, São Paulo, SP. E-mail: rngrohmann@casperlibero.edu.br.
} 
Em uma dimensão discursiva, narrativas inspiracionais (CASAQUI, 2016) e exemplares (BUONANNO, 2011) se relacionam a discursos empreendedores (GROHMANN; ROXO, 2015) no sentido de normalizar e prescrever profissionais de sucesso - ajustados ao capitalismo cool (McGUIGAN, 2009). A gramática normativa convoca os sujeitos a serem engajados, amarem o próprio trabalho, em um ajustamento à hegemonia da economia digital neoliberal (ILLOUZ, 2011; HUWS, 2014). Como afirma Sandoval (2017b) em relação ao "faça o que você ama", "o que é problemático não é a esperança de tirar prazer do seu trabalho, mas a suposição de que isso pode ser alcançado individualmente, tornando a mudança social e política obsoleta" (SANDOVAL, 2017b, p. 8).

Nesse mesmo sentido, surgem nomenclaturas como "economia do compartilhamento" e "economia de plataforma", onde se encaixam, por exemplo, iniciativas como Uber e AirBnB, também com promessas individualistas, transformando a noção de compartilhamento em mercadoria e ideologia. Conforme Fuchs (2017, p. 287), "o mundo das plataformas de compartilhamento lucrativas está longe de ser sem fricção. Suas contradições são reveladas pelas circunstâncias de novas lutas em torno dessas plataformas". Para o autor, nesse universo da "economia de compartilhamento", há a redução da questão a um fenômeno moral, um fetichismo do compartilhamento, um determinismo tecnológico e a falta de análise de classe. Deste modo, contribuiria para a própria financeirização da comunicação (LAPAVITSAS, 2013; SODRÉ, 2014; FUCHS, 2017), transformando o "compartilhamento" em modelo de acumulação capitalista.

Assim, desde a flexibilização das condições de trabalho até as mudanças nos processos produtivos e discursivos contribuem, em geral, para reforçar um establishment vindo também da crítica estética mostrada por Boltanski e Chiapello (2009). Então, como imaginar outros mundos possíveis, "utopias reais" (WRIGHT, 2010) que não deixem naturalizar o "realismo capitalista" (FISHER, 2011)?

O cooperativismo de plataforma, segundo Scholz (2016), coloca-se como uma alternativa ao ethos individualista da economia do compartilhamento, no sentido de rivalizar com empresas como Amazon e Uber. A partir disso, o presente artigo busca analisar - tendo como base as discussões sobre cooperativas, capitalismo de plataforma e cooperativismo de plataforma - iniciativas de mídia presentes no Platform.coop, referência mundial no cooperativismo de plataforma, com o intuito de compreender seus objetivos, valores e visões de mundo, com seus alcances e limites em relação à transformação social, buscando investigar até que ponto o "cooperativismo de plataforma" se apresenta com um perfil contestatório ao capitalismo.

Dentre as 241 iniciativas presentes no diretório da Platform.coop (criado pela Internet of Ownership), escolhemos as iniciativas ligadas à mídia e às comunicações por nos interessar saber como os trabalhadores da área de comunicação têm aderido ao cooperativismo de plataforma. Utilizamos como corpus de análise os textos de apresentação nos sites das iniciativas, em seções como "Sobre" ou "Quem somos". Trata-se de enunciados relacionados a valores e identidades no mundo do trabalho, enquanto marcadores de lugares de enunciação em relação ao cooperativismo e à questão da plataforma. 


\section{COOPERATIVAS: SITUANDO O DEBATE NO CAMPO}

As discussões sobre cooperativas de trabalhadores passam por clássicos como Marx (2012) e Luxemburgo (2015). Seria a cooperativa uma forma de organização do trabalho revolucionária? Enquanto Rosa Luxemburgo (2015) considera que as cooperativas são, no máximo, algo reformista em relação aos interesses do capital, justamente por não o enfrentar, Marx (2012) compreende que elas são contraditórias. "No que diz respeito às atuais sociedades cooperativas, elas só têm valor na medida em que são criações dos trabalhadores e independentes, não sendo protegidas nem pelos governos nem pelos burgueses" (MARX, 2012, p. 41). Atualmente, essa cooptação da cooperativa pelo modelo-empresa contribui, como afirma Sandoval (2016), para a despolitização das cooperativas, e a autora ressalta que essa "tendência" vem desde o século XIX.

Entre autores atuais, Wellen (2012) também sustenta que é preciso reconhecer a natureza contraditória, sem mistificar ou romantizar sua capacidade de transformação social, muitas vezes contribuindo "mais para assegurar a permanência do capitalismo do que para gerar abalos nesse sistema, sendo por esse motivo que representantes da burguesia decidiram apoiar e elogiar essas experiências" (WELLEN, 2012, p. 85). Em sua visão, a gestão, por si mesma, não impacta de forma autônoma e direta na reprodução do capitalismo, e não assegura, por si mesma, a gestão coletiva.

Já Wright (2010) concebe o cooperativismo como uma possibilidade de "utopia real", enquanto uma tensão entre sonhos e práticas, com senso de possibilidade de mudança emancipatória. Em sua visão, pode haver diversos "desenhos institucionais" para as cooperativas. Segundo Wright (2010, p. 238),

Enquanto, em princípio, em todas as cooperativas de trabalhadores, os managers prestam conta aos trabalhadores por meio de processos democráticos, em algumas cooperativas, 0 trabalho de gerenciamento é rotacionado entre os membros, enquanto em outras há uma estrutura gerencial distinta com gerentes treinados profissional e tecnicamente. Estas variações nas formas institucionais refletem adaptações às complexidades práticas de realizar os princípios da propriedade do trabalhador e da governança democrática a partir das diferentes condições.

A ideia da cooperativa como uma "utopia real" se relaciona a uma visão que permita desnaturalizar o "realismo capitalista" (FISHER, 2011), como também afirmam Dardot e Laval (2017, p. 17) em relação ao "comum": "não o ressurgimento de uma Ideia comunista eterna, mas o surgimento de uma forma nova de contestar o capitalismo, ou mesmo de considerar sua superação". Os autores franceses trabalham com as propostas de resistência cooperativa e cooperativa resistente para combater 0 comum enquanto uma categoria gerencial da governança capitalista.

Trazer novamente para o cerne da luta política a questão da organização do trabalho é a única resposta que pode ser dada às estratégias políticas da gestão neoliberal. Não basta "enriquecer as tarefas" ou "consultar" os assalariados de tempos em tempos sobre suas condições de trabalho: eles têm de participar da elaboração das regras e das decisões que os afetam (DARDOT; LAVAL, 2017, p. 517). 
Na mesma direção, De Peuter e Dyer-Witheford (2010) relacionam o comum às cooperativas, destacando que o enfoque no comum não pode se descolar da política trabalhista e de questões de desigualdade e classe. A partir disso, eles citam cinco características ideais de práticas cooperativas: trabalho associado, democracia no ambiente de trabalho, redistribuição de mais-valia, cooperação entre cooperativas e ligações entre cooperativas e Estados socialistas. Ressaltam, ainda, o papel da comunicação na criação de "bens não rivais e recursos comuns" (DE PEUTER; DYERWITHEFORD, 2010, p. 45) não somente com iniciativas liberais de Creative Commons. $\mathrm{Na}$ circulação do comum, "o momento comunicacional no meio comum envolve a interação dialógica necessária para o planejamento democrático e uma economia de associação" (DE PEUTER; DYER-WITHEFORD, 2010, p. 46).

Essas questões podem se relacionar a uma visão de cooperativa não só como "utopia real" (WRIGHT, 2010) como também de um "projeto radical" (SANDOVAL, 2017a), isto é, que não seja vista como uma "vantagem empresarial" ou modelo de negócio empreendedor, e que vá além de microiniciativas (DEAN, 2016), o que requer a construção de um movimento mais amplo de cooperativas. Segundo Sandoval (2016, p. 109), "um movimento cooperativo radical poderia ser um espaço para traduzir a política cooperativa em demanda política". Para a autora, ainda, as cooperativas radicais são baseadas em autogestão democrática e em propriedade coletiva ou comum - onde "o excedente gerado não é distribuído aos membros, mas se mantém como propriedade da cooperativa" (SANDOVAL, 2017a, p. 119). Contudo, há de se tomar o devido cuidado para não idealizar o potencial emancipatório das cooperativas, pois "transformar os trabalhadores em capitalistas pode melhorar as condições de trabalhadores individuais, mas não resolve outros problemas estruturais do capitalismo que levam a enormes desigualdades sociais e crises econômicas e ambientais" (SANDOVAL, 2017a, p. 118).

O mundo do trabalho nas áreas de cultura e comunicação não está fora desse debate. Catherine P. Mulder (2015), por exemplo, analisa os trabalhadores da cooperativa da orquestra sinfônica de Londres; Sandoval (2016; 2017a; 2017b) realiza pesquisas em cooperativas do setor cultural, que envolve os setores de mídia, artes cênicas, software e tecnologia, música, cinema, design gráfico e editoração. Especificamente no jornalismo, Siapera e Papadopoulou (2016) analisam iniciativas cooperativas jornalísticas na Grécia, embora de forma acrítica em relação ao empreendedorismo. Já Nicole Cohen (2016), que tece críticas ao jornalismo empreendedor, afirma que "o desenvolvimento de cooperativas geridas por trabalhadores para forjar novas relações entre jornalistas e audiências é promissor, pois o modelo cooperativo aprimora a autonomia e o controle dos trabalhadores" (COHEN, 2016, p. 243), além de se relacionar a um compromisso do jornalismo e dos jornalistas com os valores democráticos.

Segundo Sandoval (2017a), no trabalho na área de cultura, também é necessário levar a sério as resistências dos trabalhadores precários, "desde a organização em espaços de co-working até a união e construção de sindicatos freelancers" (SANDOVAL, 2017a, p. 115), além de movimentos mais amplos. É preciso, pois, considerar que o trabalho inserido no modo de produção capitalista está sujeito a suas pressões, com as cooperativas podendo reproduzir

\footnotetext{
${ }^{1}$ Como afirma o relatório de economia cooperativa do Reino Unido (BOYLE, 2015), ressaltando que as cooperativas impulsionam o empreendedorismo e a inovação.
} 
[...] padrões de autoexploração, trabalhando longas horas por baixos salários. Ao discutir o potencial das cooperativas em lidar com o trabalho precário, é importante reconhecer a insegurança estrutural das indústrias culturais e a precariedade dos mercados capitalistas em geral, dos quais as cooperativas não escapam (SANDOVAL, 2017a, p. 121-122).

Ressaltamos novamente, pois, o caráter contraditório das cooperativas, e, neste sentido, podemos observar como os discursos acerca do trabalho em cooperativas são modalizados, inclusive nas áreas de cultura e comunicação, desde um projeto cooperativo-empreendedor, mais próximo ao de uma startup, até outros que tenham por base um projeto político de transformação social. O relatório da Co-operatives UK para o setor de mídia (BOYLE, 2015) destaca a "solução cooperativa para a crise no setor de mídia". Encarada como um modelo de negócio, as características de uma cooperativa são elencadas como empresas confiáveis, resilientes e com melhor desempenho comercial. A cooperação é vista como "uma maneira de fornecer engajamento com pouco custo extra, porque a mudança na governança transforma a oferta. Os leitores não estão sendo convidados a consumir ou não consumir, mas a consumir, escrever, engajar-se, controlar e compartilhar" (BOYLE, 2015, p. 23). Assim, essa visão de cooperativa de mídia se aproxima à "ideologia da cultura participativa", criticada por Fuchs (2017).

Por outro lado, para autoras como Sandoval (2016; 2017a; 2017b) e Cohen (2016), apenas faz sentido falar em cooperativas nos setores de cultura e comunicação se levar em conta seu sentido político. A pesquisa de Sandoval (2017b) mostra discursos mais politizados de trabalhadores de cooperativas na área da cultura em relação ao relatório da Co-operatives UK, com os trabalhadores expressando um profundo descontentamento com as atuais condições de trabalho no setor cultural, além da desigualdade e da falta de democracia no ambiente de trabalho, de maneira geral. Eles colocam como vantagens das cooperativas as decisões serem tomadas democraticamente, a propriedade comum e a igualdade de salários. Sandoval (2017a) também relaciona a solidariedade no local do trabalho a um ambiente mais politizado. Nesse sentido, "as estruturas coletivas de trabalho podem também inspirar formas colaborativas de produção cultural que sejam mais apropriadas para a compreensão da cultura como algo comum" (SANDOVAL, 2017a, p. 122). Reconhecer, pois, ao mesmo tempo, o potencial emancipatório e a natureza contraditória das cooperativas nos auxilia a compreender seus diferentes sentidos nos discursos. Questionamo-nos, então, em que medida o chamado "cooperativismo de plataforma" pode ser distinto do "capitalismo de plataforma".

\section{TRABALHO DIGITAL: CAPITALISMO E COOPERATIVISMO DE PLATAFORMA}

A disputa de sentidos que assola a questão das cooperativas em geral também se faz presente no debate acerca do trabalho digital, por exemplo, desde a supremacia do "imaterial" (NEGRI; LAZZARATO, 2001) até o reconhecimento da materialidade do trabalho digital (HUWS, 2011; DANTAS, 2012). ${ }^{2}$ As nomeações e seus sentidos nos

\footnotetext{
${ }^{2}$ Como também afirma Scholz (2016, p. 6), "o trabalho digital pode ser tudo menos imaterial; é um setor da economia, um conjunto de atividades humanas baseado nas cadeias globais sobre a mão de obra material; trata-se de atividades humanas que têm valor econômico e são realizadas por meio de uma variedade de dispositivos em plataformas altamente monopolizadas em tempo real, numa escala verdadeiramente nova e sem precedentes".
} 
auxiliam a compreender as visões de mundo intrincadas nos jogos de enunciação. Trebor Scholz (2016) considera haver uma hegemonia da ideologia da "economia do compartilhamento", com uma retórica corporativa, capitalista e individualista acerca de compartilhamento, no sentido de mostrar uma faceta cool do capitalismo (MCGUIGAN, 2009), uma ideologia do playbour (play + labour), como afirma Küklich (2005) - artifício este usado por corporações como Google, Facebook, Uber e Amazon. Nesse sentido, como afirma Scholz (2016, p. 2), "parece que a magia do trabalho digital [...] pode ser mais prejudicial aos trabalhadores de baixa renda.

Trata-se, na verdade, do "capitalismo de plataforma", que, para Srnicek (2017), configura-se como uma ideologia californiana ${ }^{3}$ em que a plataforma surge como um "novo tipo de empresa". Para o autor, "plataformas são infraestruturas digitais que possibilitam a interação entre dois ou mais grupos" (SRNICEK, 2017, p. 43), uma série de ferramentas que possibilita aos usuários a construção de seus próprios produtos e serviços, provendo uma infraestrutura básica para realizar a mediação entre diferentes grupos. Nesse sentido, não são somente empresas de tecnologia ou internet, mas que envolvem interações digitais e também não digitais. No fundo, a "plataforma" - seja em sua versão capitalista ou cooperativa - são desdobramentos de processos históricos envolvendo o próprio modo de produção capitalista. Não podemos, pois, conceber a "plataforma" como sendo algo absolutamente descolada das condições materiais.

Não existe apenas um tipo de plataforma. Para Srnicek (2017), podemos conceber, ao menos, cinco tipos: a) plataformas publicitárias, como Google e Facebook; b) plataformas em nuvem (cloud), como AWS e Salesforce; c) plataformas industriais, como Siemens; d) plataformas de produto, como Spotify e Rolls Royce; e) plataformas lean, como Uber e AirBnB, sendo que a extração de dados ${ }^{4}$ está no centro da maioria das engrenagens das plataformas.

Para Scholz (2017), o capitalismo de plataforma "não tem sido efetivo em atender às necessidades do bem comum. O que inicialmente parecia inovação rapidamente aumentou o volume da desigualdade de renda" (SCHOLZ, 2017, p. 35), beneficiando poucos proprietários e acionistas. Scholz (2016; 2017), então, propõe o "cooperativismo de plataforma" para rivalizar com o modelo de empresas como Amazon e Uber:

[...] será que é realmente inconcebível escapar de empresas como Uber, Facebook e CrowdFlower? Uma Internet das pessoas é possível! Uma coalizão de designers, trabalhadorxs, artistas, cooperativas, desenvolvedorxs, sindicatos inovadores, advogadxs públicxs pode mudar as estruturas para que todxs possam colher os frutos do próprio trabalho (SCHOLZ, 2017, p. 45).

Com isso, as cooperativas de trabalhadores poderiam projetar suas próprias plataformas e aplicativos. Srnicek (2017) segue na mesma direção ao reivindicar uma coletivização das plataformas, em uma combinação de desenvolvimento tecnológico, participação democrática e distribuição de recursos. Para Scholz (2017), neste

\footnotetext{
${ }^{3}$ De forma similar, Schradie (2017) aborda a "ideologia do Vale do Silício" como um fundamentalismo de livre mercado, em que a crença de "que a internet inevitavelmente produziria formas mais democráticas de participação" (SCHRADIE, 2017, p. 86). Eric Sadin (2016) também aborda a silicolonisation do mundo como uma expansão do liberalismo numérico.

${ }^{4}$ Considerando a dataficação e a extração de dados como elementos essenciais na circulação do capital atualmente (TUROW; COULDRY, 2017; BREITER; HEPP, 2018).
} 
contexto, a plataforma pode ser definida como "o termo usado para descrever o ambiente no qual intermediárixs extrativxs ou cooperativxs oferecem seus serviços ou conteúdos" (SCHOLZ, 2017, p. 61). Alguns exemplos dados por Scholz (2016; 2017) são a Loconomics - que possui um aplicativo que oferece diversos serviços, como encanador, eletricista, babá e passeador de cão - e a Stocksy, cooperativa de fotógrafos e artistas visuais.

As cooperativas de plataforma, segundo Scholz (2017), podem ser de propriedade dos trabalhadores, dos produsers ou multissetoriais, e têm como princípios: a) propriedade ("plataformas cooperativas de propriedade coletiva, possuídas pelas pessoas que geram a maioria do valor nessas plataformas" [SCHOLZ, 2017, p. 78]); b) pagamentos decentes e seguridade de renda; c) transparência e portabilidade dos dados; d) apreciação e reconhecimento; e) trabalho codeterminado ("plataformas de trabalho deveriam envolver trabalhadorxs desde o momento da programação da plataforma e durante o seu uso" [SCHOLZ, 2017, p. 79-80]); f) moldura jurídica protetora; g) proteções trabalhistas portáveis e benefícios; h) proteção contra comportamento arbitrário; i) rejeição de vigilância excessiva; j) direito de se desconectar. Esses princípios pretendem fomentar a democracia no ambiente de trabalho (como um dos elementos levantados por De Peuter e Dyer-Witheford [2010]), coibindo também desigualdades de gênero e raça, por exemplo, e incentivando mecanismos de defesa do trabalho.

O que podemos notar com esse debate é uma disputa de sentidos que envolve tanto a expressão "plataforma" (entre capitalismo e cooperativismo) quanto a do próprio "cooperativismo", pois, na visão de Scholz (2016; 2017), o cooperativismo "tradicional" (com grifos para a marca discursiva) precisaria se adaptar para adentrar os ambientes digitais e as plataformas, como um embate entre uma cooperativa "ultrapassada" e outra "moderna", cool. O que podemos notar é que, diferentemente do postulado por Sandoval (2016; 2017a; 2017b) e Cohen (2016), não está em primeiro plano nas proposições de Scholz (2016; 2017) transformações políticas em prol de "utopias reais" (WRIGHT, 2010) ou projetos radicais, por exemplo. Se, como já afirmamos, as cooperativas já são de natureza contraditória, o cooperativismo de plataforma acentua essa característica. Essa diferença de matizes nos parece essencial para procurar compreender que sentidos de cooperativas são atribuídas pelas iniciativas de mídia presentes no Platform.coop, pois, como afirma Fuchs (2017, p. 310), "uma cooperativa não é um aplicativo solucionador que pode abolir os problemas do capitalismo quando combinado com tecnologias de internet". Com isso, pode ser que o "cooperativismo de plataforma" apresente mais semelhanças em relação ao "capitalismo de plataforma" que a cooperativas tradicionais contestatórias.

\section{ANÁLISE DE COOPERATIVAS DE PLATAFORMA DE MÍDIA}

O site Platform.coop é a referência em cooperativismo de plataforma, criado por Trebor Scholz. O slogan da página é: "apoiando o ecossistema do cooperativismo de plataforma" e apresenta um diretório com 241 iniciativas (no mês de janeiro de 2018). Entre elas, 83 estão na América do Norte e 74 na Europa. ${ }^{5}$ Um predomínio do Norte global e principalmente de países como Estados Unidos, Reino Unido, França e Canadá. Para a presente análise, foram selecionadas oito iniciativas de mídia

\footnotetext{
${ }^{5}$ Há de se considerar que, no mapa, nem todas as iniciativas aparecem, pois não há uma sede fixa.
} 
presentes na plataforma, selecionadas a partir de tags como media e news: Branyan Project, Co-operative News, Demcra, Design is Political, Media Co-op, NewScoop YYC, Positive News e Shareable.

O corpus, que representa apenas $3,3 \%$ do universo de iniciativas presentes no site, indica que a área de comunicação não tem uma presença forte no cooperativismo de plataforma. Para fins de análise, isso não se configura como um problema, pois estamos mais interessados na produção de sentidos e menos em questões quantitativas. ${ }^{6}$ Contudo, essas não são as únicas iniciativas de cooperativas no setor de mídia no mundo. Há, por exemplo, apenas no jornalismo, Eldiario.es (Espanha), Tiempo Argentino (Argentina), Lavaca (Argentina), The Bristol Cable (Reino Unido) e EfimeridaSyntakton - EFSYN (Grécia), que não se reivindicam como cooperativas de plataforma. O corpus, então, revela as particularidades das iniciativas que se denominam "cooperativas de plataforma". A análise foi realizada a partir dos enunciados de apresentação nas páginas das cooperativas. Isso significa que a abordagem recai sobre o que a cooperativa diz sobre si mesma, como marcas enunciativas ${ }^{7}$ que se relacionam a um ethos, deixando, pois, vestígios e rastros de sentidos discursivos em relação a como compreendem o trabalho cooperativo, e se isso se aproxima mais dos sentidos atribuídos por Sandoval (2016; 2017a; 2017b), Scholz $(2016 ; 2017)$ ou pelo relatório da Co-operatives UK para o setor de mídia (BOYLE, 2015), por exemplo. ${ }^{8}$

Como todas as iniciativas se encontram no site Platform.Coop, iniciamos a análise pelo texto de apresentação da própria plataforma. Expressões como "política" ou "transformação" não são mencionadas, enquanto há a predominância de enunciados que contêm "novos modelos de negócio" e "negócios democráticos". Os regimes de visibilidade no discurso se relacionam às conexões entre as cooperativas e a economia digital, como se esta fosse alheia à economia de maneira geral, como um mito da "economia imaterial" (HUWS, 2011). A predominância de um discurso do mercado sobre a política é revelada também no seguinte enunciado: "As cooperativas existentes podem criar mercados on-line para competir melhor com os monopólios existentes" (Platform.Coop). A vantagem da cooperativa residiria, portanto, em uma vantagem competitiva de mercado. Um exemplo é a cooperativa Cosmos, cujo slogan é: "uma cooperativa com tendências visionárias". Desta forma, os enunciados se relacionam, em alguma medida, com discursos provenientes de startups e do próprio relatório de Boyle (2015). O discurso mercadológico é matizado somente com a ressalva que as cooperativas favorecem um ambiente de trabalho mais diversificado e livre. Neste sentido, os enunciados da Platform.Coop se assemelham aos discursos dos empreendedores sociais, como mostram Casaqui e Sinato (2015, p. 92), com o ethos sendo enunciado como uma mistura de Richard Branson - empresário bilionário - e Madre Teresa de Calcutá:

Os discursos que representam esse ator social defendem sua capacidade revolucionária de mudar radicalmente o mundo,

\footnotetext{
${ }^{6}$ Não procedemos uma análise de conteúdo de cunho quantitativo por palavras-chave, mas uma análise das ideologias (BACCEGA, 1998; FUCHS, 2017) presentes nas páginas de apresentação, de maneira a revelar o ethos que a iniciativa apresenta em relação a valores cooperativistas e da sociedade em geral.

7 Como afirma Baccega (1998, p. 95), "na enunciação estão as marcas das condições de vida de um grupo, de uma classe social, as quais originam a condição de maior ou menos abstração, de maior ou menor generalização no uso da palavra".

${ }^{8}$ Todos os enunciados analisados foram traduzidos livremente para o português.
} 
eliminar suas mazelas - sem, no entanto, abalar as estruturas do sistema que o concebe. A revolução se dá somente no plano discursivo, visto que, na prática, há a perspectiva de uma reforma e manutenção do sistema capitalista, consequentemente, com a permanência, mesmo que involuntária, de suas incoerências e desigualdades.

Desta forma, trata-se mais de um ajustamento discursivo às prescrições do capitalismo cool (McGUIGAN, 2009).

Dentre as oito iniciativas de mídia analisadas, três possuem mais fortemente um discurso relacionado às "narrativas inspiracionais" (CASAQUI, 2016), com toda uma gramática envolvendo criatividade, disrupção, compartilhamento e empreendedorismo cívico, por exemplo: "Nesta era disruptiva da internet, os jornais locais estão morrendo mais rápido do que os sites de notícias sobre as comunidades" (Banyan Project); "engajamento cívico e colaboração editorial” (Banyan Project); "Inspire, crie, mude. Nossa missão é encorajar e capacitar todo mundo a usar a curiosidade criativa para resolver problemas sociais e tornar o mundo um lugar melhor. Estamos em uma missão para mudar a cultura da criatividade" (Design is Political); "Centro de notícias, ação e conexão sem fins lucrativos direcionado para a transformação do compartilhamento. Qual é a transformação de compartilhamento? É um movimento de movimentos que emerge das bases para resolver os maiores desafios de hoje, que as antigas instituições estão falhando em resolver" (Shareable).

Por esses enunciados, podemos perceber que a ruptura é menos com a sociedade e com a política vigentes e mais a "crítica estética" abordada por Boltanski e Chiapello (2009). Desta forma, parecem se relacionar mais a um tipo de "capitalismo de plataforma" do que necessariamente do cooperativismo, ao menos enquanto um projeto radical. Agora, observaremos o perfil das iniciativas, sua relação com a organização cooperativa e com a área em que atuam (comunicação).

O Co-operative News é o jornal cooperativo mais antigo do mundo, tendo sido criado em 1871. A Media Co-op é uma rede de cooperativas de mídia local dedicada a fornecer cobertura jornalística sobre comunidades do Canadá. A NewScoop YYC é uma cooperativa jornalística da cidade de Calgary, também no Canadá, focado em cobertura sobre a cidade, com o slogan de "cidade próspera". A Positive News se coloca como a primeira cooperativa global de mídia fomentada por crowdfunding, de propriedade dos leitores e dos jornalistas. O Demcra é um site comunitário sem fins lucrativos destinado a compartilhamento e discussões de links. As iniciativas Design is Political, Banyan Project e Shareable são apoiadoras de cooperativas. Banyan é uma organização sem fins lucrativos fundada por jornalistas sêniores, sociólogos e desenvolvedores web com missão de fortalecimento da democracia; Design is Political busca promover "tecnologia cívica" e tecnologias para o bem e para o desenvolvimento de cooperativas relacionadas à área de design; Shareable é um centro sem fins lucrativos de notícias, ação e conexão direcionado ao que chamam de "transformação do compartilhamento". A partir desses perfis, podemos observar duas tendências no "cooperativismo de plataforma" na área de mídia: por um lado, iniciativas jornalísticas, de cunho local ou comunitário, e por outro, apoiadoras que pretendem impulsionar o cooperativismo de plataforma, fornecendo ferramentas tecnológicas e de organização do trabalho.

Com relação ao tipo de cooperativa, há cooperativas de consumo (como Banyan), multissetoriais (Positive News, NewScoop, Media Co-op) e de trabalhadores (Cooperative News). As outras não elencam, em seus textos de apresentação, detalhes sobre como a cooperativa se organiza. No Banyan Project, os leitores possuem 
igualdade de decisão e elegem os conselheiros das cooperativas de notícias locais. A iniciativa ressalta as expressões "engajamento" e "confiança" para se referir às vantagens da cooperativa em uma "era de distanciamento e desconfiança". Segundo seu texto de apresentação, "as cooperativas independentes de notícias associadas ao Banyan serão conduzidas profissionalmente e governadas democraticamente" (Banyan). Neste sentido, mostra como a diferença estaria na "governança democrática", mas o jornalismo continuaria a ser produzido "profissionalmente". A ênfase no ambiente democrático também foi colocada por NewScoop, Co-operative News e Positive News. A Banyan ainda é a única a ressaltar que consta em seu centro de serviços uma plataforma de software adaptada para as cooperativas jornalísticas afiliadas, como no enunciado a seguir: "A equipe do Banyan ajudará os afiliados a aproveitar ao máximo os recursos distintivos da plataforma, que são projetados para ampliar o impacto de seu jornalismo, enriquecer o envolvimento cívico e criar membros cooperativos" (Banyan).

A Media Co-op é financiada pelos leitores e administrado pelos membros, que podem ser de três tipos: leitores, colaboradores ou editores, sendo que estes últimos são os encarregados pela organização cotidiana da cooperativa. A iniciativa afirma procurar representar os interesses comuns de cada um desses setores. Uma das questões comuns atualmente é o financiamento de jornalistas experientes para produção de reportagens em profundidade. Como se trata de uma rede de cooperativas, cada local tem um grau de autonomia, mas também contribui para a operação da cooperativa como um todo: "em consulta aos membros, os grupos editoriais locais decidem como usar recursos em sua área" (Media Co-op). A NewScoop apresenta um modelo semelhante, multissetorial, declarado como "modelo sustentável de propriedade e negócios" (New Scoop), colocando como vantagem a governança democrática. A iniciativa ressalta seu caráter sem fins lucrativos e que não é necessário atender às agendas financeiras dos acionistas.

A Positive News também apresenta um modelo multissetorial, mas baseado em crowdfunding, e trabalha com funções de um jornal tradicional, como editor-chefe, por exemplo, que diz o seguinte: "o nível de investimento que tivemos, o número de co-proprietários que temos agora e as mensagens emocionantes de apoio que nos enviaram, mostram um profundo e generalizado desejo de uma mídia mais inspiradora" (Positive News). São ressaltadas questões de ordem financeira - sem falar números, mas trazendo ao primeiro plano a grande adesão à iniciativa - e também inspiracionais (CASAQUI, 2016). O investimento mínimo é de 50 libras e, segundo a iniciativa, cada acionista terá voto igual na cooperativa - como em eleições de conselheiros -, não importando a quantia investida.

Com relação às atividades desempenhadas pelas cooperativas, ou seja, "o que dizemos que fazemos", são valorizadas expressões como "jornalismo participativo" (Media Co-op), "jornalismo criativo" (Design is Political; NewsScoop), "compartilhamento" (Shareable; Positive News) - que se relacionariam mais à ideia de "plataforma" do que efetivamente de "cooperativismo". A única palavra que resvala em um sentido mais político é a de "democracia", que só aparece no Banyan Project, como uma iniciativa que visa fortalecer a democracia pois meio da união de cooperativas de jornalismo, área que também é essencial para a democracia, em sua visão.

Uma gramática positiva (HAN, 2017) e inspiracional (CASAQUI, 2016) também abrange os conteúdos midiáticos. A Design is Political, por exemplo, abrange áreas como dados abertos, terceiro setor e inclusão digital a partir de três seções: "inspire, crie e altere": "dê uma olhada em como campanhas, ferramentas e plataformas criativas 
influenciaram a formulação de políticas e capacitaram pessoas para grandes mudanças sociais" (Design is Political). Isto é, em sua visão, as plataformas (e a criatividade) impulsionam mudanças sociais, como se a tecnologia, e não a sociedade, fosse o motor da história (PINTO, 2005; AMPUJA, 2015). Nesse sentido, os conteúdos têm de veicular inspiração e também positividade: "não podemos esperar para trazer a vocês ainda mais das nossas reportagens positivas e iluminar os caminhos para um mundo florescente" (Positive News); "nós vimos a transformação acontecer em pessoas de todos os setores da vida. É por isso que fazemos o que fazemos. É por isso que acreditamos que a transformação por meio do compartilhamento é imparável" (Shareable). Neste sentido, assemelha-se à sociedade da transparência e da positividade criticada por Han (2017): "A sociedade positiva evita todo e qualquer tipo de negatividade, pois esta paralisa a comunicação. Seu valor é medido apenas pela quantidade e velocidade da troca de informações"

\section{CONSIDERAÇÕES FINAIS}

As cooperativas, como vimos, possuem um caráter contraditório desde as suas primeiras iniciativas, devido aos seus modos de inserção no sistema capitalista. As contradições se acentuam no estágio atual do capitalismo, com projetos distintos como os de cooperativismo de plataforma e a cooperativa como um projeto radical, ambos com existência em projetos midiáticos e digitais. O acento desta última está na transformação política e social, procurando desnaturalizar o "realismo capitalista" (FISHER, 2011). Já o cooperativismo de plataforma, embora possua um acento mais crítico teoricamente a partir de Scholz (2016; 2017), principalmente em sua contraposição em relação à "economia do compartilhamento", mostra - tanto no texto de abertura da Platform.Coop quanto nos enunciados das iniciativas de mídia presentes no site - que seus lugares de enunciação estão marcados por uma gramática da startup, em que as tecnologias são colocadas como "salvadoras" de um modelo, e são invisibilizadas expressões ligadas à transformação política, salvo "democracia". Abordam que há democracia no mundo do trabalho, mas não dão detalhes sobre o trabalho associativo e não se mencionam a redistribuição de maisvalia ou a questão do "comum", para elencar os pontos citados por De Peuter e DyerWitheford (2010).

Esse cenário já é de alguma forma expresso também pelo relatório da Co-operatives UK para o setor de mídia (BOYLE, 2015), que não se alinha à nomenclatura de "cooperativismo de plataforma", com as cooperativas sendo tratadas mais como uma solução de negócios do que uma atividade política. São colocadas, então, em contraposição um modelo "tradicional" e dito ultrapassado de cooperativa versus um modelo "modernizado" e atualizado, relacionado às tecnologias e mídias digitais e ao que há de mais "inovador" em questão de modelos de negócios.

Por um lado, é necessário enfatizar a importância da organização coletiva e formas alternativas de organização do trabalho na área de comunicação, que impeçam a flexibilização - junto com individualização e precarização - do trabalho no modelo hegemônico neoliberal atual. Por outro, o debate não é nem se é "reforma ou revolução" (LUXEMBURGO, 2015), mas em que medida o cooperativismo de plataforma, a partir dos enunciados das iniciativas de mídia, coloca-se como mais "plataforma" do que efetivamente "cooperativa", ajustando-se às prescrições do capitalismo cool (MGUIGAN, 2009). Assim, perguntamo-nos em que medida o cooperativismo de plataforma estaria mais próximo discursivamente ao capitalismo de plataforma do que se pode imaginar. 


\section{REFERÊNCIAS}

AMPUJA, Marko. A sociedade em rede, o cosmopolitismo e o "Sublime digital": reflexões sobre como a história tem sido esquecida na teoria social contemporânea. Parágrafo, v. 1, n. 3, p. 55-67, 2015.

BACCEGA, Maria Aparecida. Comunicação e linguagem: discursos e ciência. São Paulo: Moderna, 1998.

BOLTANSKI, Luc; CHIAPELLO, Ève. O novo espírito do capitalismo. São Paulo: Martins Fontes, 2009.

BREITER, Andreas; HEPP, Andreas. The complexity of datafication: putting digital traces in context. In: HEPP, Andreas; BREITER, Andreas; HASEBRINK, Uwe (Org.). Communicative figurations: transforming communications. London: Palgrave, 2018. p. 387-405.

BOYLE, Dave. Good news: a co-operation solution to media crisis. Manchester: Cooperatives UK, 2015.

BUONANNO, Milly. Histórias de vida exemplares: biografias. MATRIZes, n. 5, v. 1, p. 6384, jul./dez. 2011.

CASAQUI, Vander. A inspiração como forma comunicacional do capitalismo "cool". In: CONGRESSO BRASILEIRO DE CIÊNCIAS DA COMUNICAÇÃO, 39., 2016, São Paulo. Anais... São Paulo: Intercom, 2016.

CASAQUI, Vander; LIMA, Manolita; RIEGEL, Viviane (Org.). Trabalho em publicidade e propaganda. São Paulo: Atlas, 2011.

CASAQUI, Vander; SINATO, Angelina. Empreendedorismo social em perspectiva global: bem comum, trabalho e engajamento na retórica do capitalismo contemporâneo. Revista Eptic, v. 17, n. 1, p. 185-198, jan, /abr. 2015.

COHEN, Nicole. Writers' rights: freelance journalism in a digital age. Montreal: McGill, 2016.

DANTAS, Marcos. Trabalho com informação: valor, acumulação, apropriação nas redes do capital. Rio de Janeiro: Escola de Comunicação, Centro de Filosofia e Ciências Humanas da UFRJ, 2012.

DARDOT, Pierre; LAVAL, Christian. Comum: ensaio sobre a revolução no século XXI. São Paulo: Boitempo, 2017.

DEAN, Jodi. Crowds and party. London: Verso, 2016.

DE PEUTER, Greig; DYER-WITHEFORD, Nick. Commons and cooperatives. Affinities: a journal of radical theory, culture, and action, v. 4, n. 1, p. 30-56, 2010.

FIGARO, Roseli; NONATO, Cláudia; GROHMANN, Rafael. As mudanças no mundo do trabalho do jornalista. São Paulo: Atlas, 2013.

FISHER, Mark. Capitalist realism: is there no alternative? Winchester, UK: Zero Books, 2011.

FUCHS, Christian. Social media: a critical introduction. 2. ed. London: Routledge, 2017. 
GROHMANN, Rafael; ROXO, Michelle. Os discursos sobre o jornalista-empreendedor em sites especializados na cobertura do campo profissional. Contemporânea, v. 13, n. 2, 2015.

HAN, Byung-Chul. Sociedade da transparência. Petrópolis: Vozes, 2017.

HESMONDHALGH, David. The cultural industries. London: Sage, 2013.

HUWS, Ursula. Mundo material: o mito da economia imaterial. Mediações: revista de ciências sociais, v. 16, n. 1, p. 24-54, jan./jun. 2011.

. Labor in the global digital economy: the cybertariat comes of age. New York: Monthly Review Press, 2014.

ILLOUZ, Eva. O amor nos tempos de capitalismo. Rio de Janeiro: Zahar, 2011.

KÜKLICH, Julian. Precarious playbour: modders and the digital games industry. Fibreculture Journal, v. 3, n. 5, 2005.

LAPAVITSAS, Costas. Profiting without producing: how finance exploits us all. New York: Verso, 2013.

LUXEMBURGO, Rosa. Reforma ou revolução. São Paulo: Expressão Popular, 2015.

MARX, Karl. Crítica do programa de Gotha. São Paulo: Boitempo, 2012.

MCGUIGAN, Jim. Cool capitalism. New York: Pluto Press, 2009.

MCKERCHER, Catherine; MOSCO, Vincent. The laboring of communication: will knowledge workers of the world unite? Lanham, MD: Lexington Books, 2009.

MICK, Jacques; LIMA, Samuel. Perfil do jornalista brasileiro. Florianópolis: Insular, 2013.

MULDER, Catherine P. Transcending capitalism through cooperative practices. London: Palgrave, 2015.

NEGRI, Antonio; LAZZARATO. Trabalho imaterial: formas de vida e produção de subjetividade. Rio de Janeiro: DP\&A, 2011.

PINTO, Álvaro Vieira. O conceito de tecnologia. Rio de Janeiro: Contraponto, 2005. v. 1.

SADIN, Eric. La silicolonisation du monde: l'irrésistible expansion du liberalisme numérique. Paris: Éditions L’Échappé, 2016.

SANDOVAL, Marisol. What would Rosa do? Co-operatives and radical politics. Soundings, n. 63, 2016.

. Enfrentando a precariedade com cooperação: cooperativas de trabalhadores no setor cultural. Parágrafo, v. 5, n. 1, $2017 a$.

. From passionate labour to compassionate work: cultural co-ops, do what you love and social change. European Journal of Cultural Studies, v. 21, n. 2, 2017b.

SCHOLZ, Trebor. Uberworked and underpaid. London: Polity Press, 2016.

- Cooperativismo de plataforma: contestando a economia do compartilhamento corporativa. São Paulo: Fundação Rosa Luxemburgo, 2017.

SCHRADIE, Jen. Ideologia do Vale do Silício e desigualdades de classe: um imposto virtual em relação à política digital. Parágrafo, v. 5, n. 1, 2017. 
SIAPERA, Eugenia; PAPADOPOULOU, Lambrini. Entrepreneurialism or cooperativism? An exploration of cooperative journalistic enterprises. Journalism Practice, v. 10, n. 2, 2016.

SODRÉ, Muniz. A ciência do comum: notas para o método comunicacional. Petrópolis: Vozes, 2014.

SRNICEK, Nick. Platform capitalism. London: Polity, 2017

TUROW, Joseph; COULDRY, Nick. Media as data extraction: towards a new map of a transformed communications field. Journal of Communication, v. 68, n. 2, Apr. 2017.

WELLEN, Henrique. Para a crítica da "economia solidária". São Paulo: Expressão Popular, 2012.

WRIGHT, Erik Olin. Envisioning real utopias. New York: Penso, 2010. 